NOTE

\title{
Water flow facilitates recovery from bleaching in the coral Stylophora pistillata
}

\author{
T. Nakamura ${ }^{1}$, H. Yamasaki ${ }^{1}$, R. van Woesik ${ }^{2, *}$ \\ ${ }^{1}$ Laboratory of Cell and Functional Biology, Faculty of Science, University of the Ryukyus, Senbaru 1, Nishihara, Okinawa 903-0213, Japan \\ ${ }^{2}$ Department of Biological Sciences, Florida Institute of Technology, 150 West University Boulevard, Melbourne, Florida 32901-6975, USA
}

\begin{abstract}
Exposing partially bleached samples of Stylophora pistillata coral colonies to controlled water-flow treatments revealed differential recovery rates that varied in accordance with flow rate. Recovery of the number of zooxanthellae per unit area and chlorophyll a concentrations increased rapidly in moderate-flow treatments (of $20 \mathrm{~cm} \mathrm{~s}^{-1}$ ), after an initial $3 \mathrm{wk}$ of stasis. Colonies in low-flow treatments $\left(\leq 3 \mathrm{~cm} \mathrm{~s}^{-1}\right.$ ) remained pale for the entire $7 \mathrm{wk}$ experimental period and showed only slight increases in zooxanthellae per unit area. In an earlier study, we showed that when corals were subjected to high temperature and high irradiance, coral bleaching occurred in low-flow but not in moderate-flow treatments; the present study shows that recovery from bleaching is facilitated by flow treatment. In combination, prevention of and rapid recovery from bleaching by enhanced water flow suggest that the mechanisms that lead to dysfunction of the algae-coral symbiosis are driven by mass-transfer-limited processes.
\end{abstract}

KEY WORDS: Corals $\cdot$ Bleaching $\cdot$ Water flow $\cdot$ Recovery

Resale or republication not permitted without written consent of the publisher

Coral bleaching is the loss of symbiotic algae (i.e. zooxanthellae) and/or pigment because of stress at and above the corals' acclimation capacity (Hoegh-Guldberg \& Smith 1989, Glynn 1991, 1993, Fitt \& Warner 1995, Brown 1997, Kuroki \& Van Woesik 1999). Coral bleaching may be temporary or lead to coral mortality. Higher-than-average sea surface temperatures (SSTs) have been suggested as the primary causative agent of large-scale coral bleaching events, as seen in 1997 and 1998. High irradiance seemingly acts as a secondary factor (Jones et al. 1998, Hoegh-Guldberg 1999, Warner et al. 1999), and in some coral species high SSTs can cause the onset of virulence in coralassociated bacteria which reduce endosymbiotic zooxanthellae populations (Kushmaro et al. 1996).

In contrast, rapid water flow facilitates coral survival under high irradiance and high SSTs (Nakamura \&
Van Woesik 2001). Differential rates of water flow are largely a consequence of the effect of frictional drag across the corals' boundary layers thereby changing mass-transfer rates of gases and metabolites (Patterson et al. 1989, Atkinson \& Bilger 1992, Patterson 1992). When water-flow rates are low, diffusive boundary layers are thick and passive diffusion is restricted and slow. Several coral studies have shown a positive correlation with water-flow rates and rates of (1) photosynthesis (Dennison \& Barnes 1988, Lesser et al. 1994), (2) growth (Jokiel 1978), (3) phosphate uptake (Atkinson \& Bilger 1992, Hearn et al. 2001), (4) micosporine-like amino acid accumulation under ultraviolet light exposure (Kuffner 2001, 2002) and (5) survival under high irradiance and SSTs (Nakamura \& Van Woesik 2001). There has been little study of the effects of water motion on coral recovery from bleaching. The present study used partially bleached coral samples to investigate the effect of differential water flow upon recovery of chlorophyll concentrations and symbiotic algae populations.

Materials and methods. In March 2002, 3 colonies of Stylophora pistillata were collected from Cape Kyann and 3 from Oku in the Ryukyu Islands, southern Japan (>10 m depth, irradiance about $100 \mu \mathrm{mol}$ photons $\mathrm{m}^{-2}$ $\mathrm{s}^{-1}$ ). After $1 \mathrm{wk}$ in an open flow-through water table with light at $<300 \mu \mathrm{mol}$ photons $\mathrm{m}^{-2} \mathrm{~s}^{-1}$ (a neural shading mesh reduced photosynthetically active radiation to $23 \%$ of the mid-day maximum), the colonies were separated into small 3 to $4 \mathrm{~cm}$ nubbins. They were immediately attached to small polycarbonate screws using gel high-speed super glue ('alone-alpha'); colony origin was tracked using color-coded screws. Samples were kept in this condition (i.e. $\leq 3 \mathrm{~cm} \mathrm{~s}^{-1}$ flow, $<300 \mu \mathrm{mol}$ photons $\mathrm{m}^{-2} \mathrm{~s}^{-1}$, average water temperature $27.7^{\circ} \mathrm{C}$ ) for the next 4 mo prior to experimental manipulation. Irradiance levels were measured 


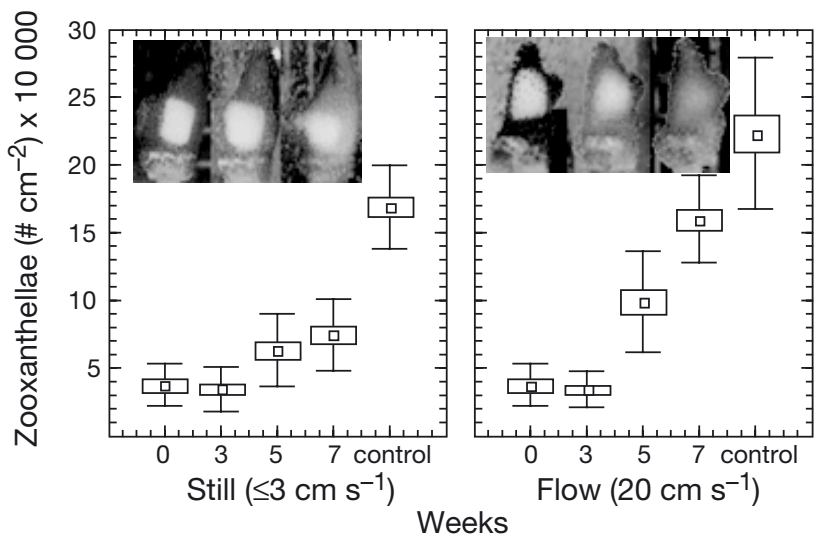

Fig. 1. Stylophora pistillata. Number of zooxanthellae (no. of cells $\mathrm{cm}^{2}$ surface area of living tissue $)$ in still $\left(\leq 3 \mathrm{~cm} \mathrm{~s}^{-1}\right)$ and flow $\left(20 \mathrm{~cm} \mathrm{~s}^{-1}\right)$ treatments over $7 \mathrm{wk}(\mathrm{n}=3)$. ( $\left.\square\right)$ means, $(\square)$ SE, whiskers: SD. Photos show initial (left), 5 wk (middle), and $7 \mathrm{wk}$ (right) samples. Control groups were not bleached and were placed in each flume for same experimental time period $(7 \mathrm{wk}, \mathrm{n}=3)$

with a micro-photon sensor on a DIVING-PAM fluorometer (Waltz).

Artificial bleaching was induced by maintaining the corals under water and exposing a small $\left(1.0 \mathrm{~cm}^{2}\right)$ smooth surface of each sample to $1500 \mu \mathrm{mol}$ photons $\mathrm{m}^{-2} \mathrm{~s}^{-1}$ of light while covering the rest of the coral surface with aluminum foil for $6 \mathrm{~h}$ (method adapted from that of Yamasaki et al. [1995] for tropical higher plants). Partial colony bleaching, similar that induced by this experimental procedure, is common during sublethal thermal stress events, as evidenced on the Great Barrier Reef (Heron Island) in February 2002 (van Woesik pers. obs.). To generate this high light level, we used cold-lighting fiber-optic tubes equipped with a UV filter (NPI, Picl-nex; Phillips, projection lamp $150 \mathrm{~W})$ placed $3 \mathrm{~cm}$ above the surface of the water. Samples were immersed and held close $(1 \mathrm{~cm})$ to the surface of a 51 water bath (TAITEC, SM-05R) supplied with filtered seawater; temperature was maintained at $27^{\circ} \mathrm{C}$ by a thermostat and homogenizing propeller. After artificial bleaching, 3 samples $(\mathrm{n}=1$ for each colony) were frozen and subsequently analyzed for chlorophyll $a$ and $c_{2}$ concentrations, and zooxanthellae numbers were counted and recorded as Week 0 .

Perspex miniflumes (length $140 \mathrm{~cm}$, width $10 \mathrm{~cm}$, height $10 \mathrm{~cm}$, depth 5 to $6 \mathrm{~cm}$ ) were adapted from those described by Atkinson \& Bilger (1992). Two miniflumes were supported on concrete blocks within an open aquarium (length $2.0 \mathrm{~m}$, width $1.5 \mathrm{~m}$, depth $0.5 \mathrm{~m})$ supplied with running seawater. Water flowrate treatments were maintained at (hereinafter classified as 'still') $\leq 3 \mathrm{~cm} \mathrm{~s}^{-1}$ (hereinafter classified as 'flow') $20 \mathrm{~cm} \mathrm{~s}^{-1}$ and at an irradiance level of $300 \mu \mathrm{mol}$ pho- tons $\mathrm{m}^{-2} \mathrm{~s}^{-1}$. On June 29, 2002, 36 samples (6 samples from each colony per treatment) were placed in the flumes following artificial bleaching treatment. Additionally, 6 unbleached control samples (3 for each treatment; $\mathrm{n}=1$ for each colony) were placed in the flumes for $7 \mathrm{wk}$. The water-flow rates were generated and maintained with submersible pumps (REI-SEA, Type RSD-40).

On July 20 (Week 3) and August 4 (Week 5 ), 2 samples were taken from each colony (i.e. a total of 12 samples, 6 from each treatment). On August 21 (Week 7), 6 samples and 3 controls were taken from each treatment $(n=18)$. These nubbins were immediately frozen in $-20^{\circ} \mathrm{C}$, and taken to the laboratory to measure the number of zooxanthellae per tissue area, and chlorophyll $a$ and $c_{2}$ concentrations. To determine the number of zooxanthellae, bleached tissue was removed from skeletons with a Water-pik (Johannes \& Wiebe 1970). The water-piked liquid was centrifuged at $15000 \times g$ for $15 \mathrm{~min}\left(10^{\circ} \mathrm{C}\right)$, the top clear layer was discarded after centrifugation, and the remaining zooxanthellae pellets were resuspended in $10 \mathrm{ml}$ of filtered seawater. Centrifugation was repeated 3 times. Subsamples were then taken for hemocytometer counts. Three replicates were taken from each waterpik product. The number of zooxanthellae was expressed as the number of cells $\mathrm{cm}^{-2}$ surface area of living tissue. Surface area was estimated with the aluminum foil method (Marsh 1970). For chlorophyll extraction, $90 \%$ acetone was added to zooxanthellae pellets after 3 repeated washing centrifugations. The samples were left in the dark at 7 to $10^{\circ} \mathrm{C}$ for $48 \mathrm{~h}$. The extracted solution was centrifuged to exclude the sus-

Table 1. Stylophora pistillata. Two-way analysis of variance (ANOVA) of changes in number of zooxanthellae $\mathrm{cm}^{2}$ surface area of living tissue, chlorophyll $a$, and chlorophyll $c_{2}$, where both flow and colony are fixed effects

\begin{tabular}{|lcccc|}
\hline 2-way ANOVA & df & MS & $F$ & p-level \\
\hline Zooxanthellae nos. & & & & \\
$\quad$ Flow (F) & 1 & $280 \times 10^{8}$ & 33.640 & 0.001 \\
$\quad$ Colony (C) & 2 & $633 \times 10^{6}$ & 0.760 & 0.001 \\
$\quad$ F $\times$ C & 2 & $143 \times 10^{7}$ & 1.720 & 0.257 \\
$\quad$ Error & 6 & $833 \times 10^{6}$ & & \\
Chlorophyll a & & & & \\
$\quad$ Flow (F) & 1 & 17.558 & 352.851 & 0.001 \\
Colony (C) & 2 & 0.089 & 1.792 & 0.245 \\
F $\times$ C & 2 & 0.047 & 0.940 & 0.441 \\
$\quad$ Error & 6 & 0.050 & & \\
Chlorophyll $\boldsymbol{c}_{2}$ & & & & \\
$\quad$ Flow (F) & 1 & 0.181 & 6.179 & 0.047 \\
Colony (C) & 2 & 0.031 & 1.059 & 0.404 \\
$\quad$ F $\times$ C & 2 & 0.084 & 2.854 & 0.135 \\
Error & 6 & 0.029 & & \\
& & & & \\
\hline
\end{tabular}



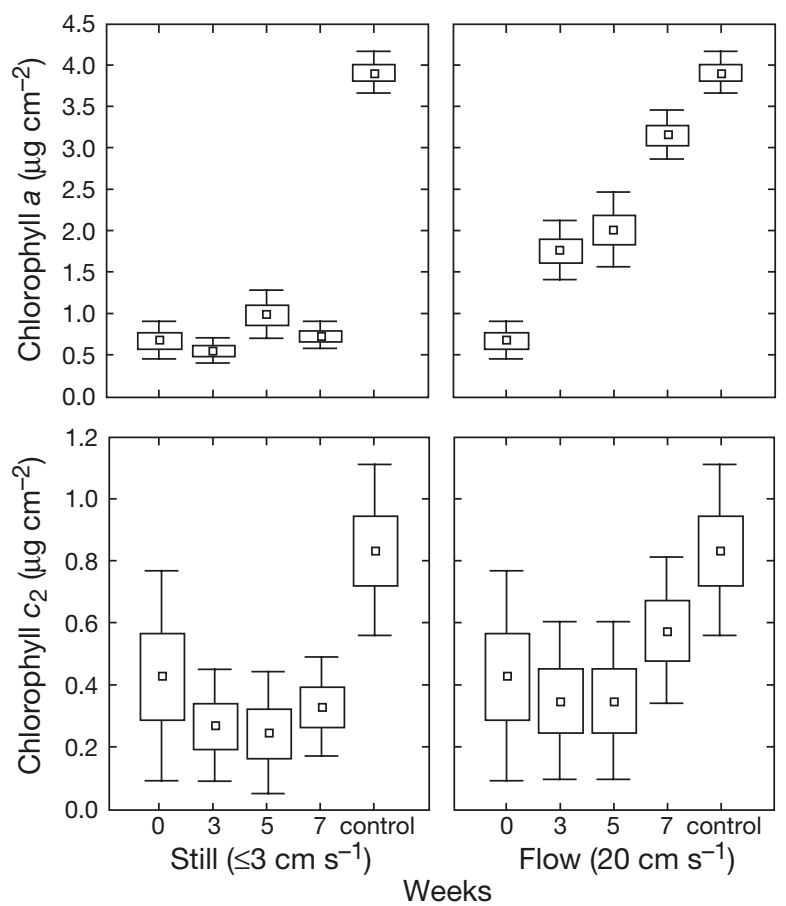

Fig. 2. Stylophora pistillata. Changes in chlorophyll a and $c_{2}$ concentrations in still and flow treatments over 7 wk $(n=3)$. Symbols as in Fig. 1

pended matter prior to spectrophotometer measurements. Chl $a$ and $C_{2}$ concentrations were calculated using the equations of Jeffrey \& Humphrey (1975).

Using the final Week 7 measurements, 2-way ANOVAs were used to examine the effects of flow and genotype (colony) on (1) the number of zooxanthellae per area, (2) chlorophyll a concentration, and (3) chlorophyll $C_{2}$ concentration.

Results. High-light treatments caused sample surfaces to pale within $6 \mathrm{~h}$, except the tentacles, which paled within $24 \mathrm{~h}$. Immediate sampling revealed that chlorophyll concentration per zooxanthella did not change, which suggests that paling was a consequence of zooxanthellae loss. The number of zooxanthellae per unit area remained similar for $3 \mathrm{wk}$ for both treatments (i.e. still and flow conditions, at $\leq 3$ and $20 \mathrm{~cm} \mathrm{~s}^{-1}$ respectively), and then gradually increased in the flow-treated colonies only (Fig. 1; Table 1). Notably, there were considerable differences in the number of zooxanthellae per unit area for the controls, with stilltreatment controls supporting fewer zooxanthellae (Fig. 1). Flow-treated colonies regained as much as $70 \%$ of the control group chlorophyll concentration within $7 \mathrm{wk}$, while still-treated colonies stayed pale for the entire experimental period (Fig. 2); this difference was significant, particularly for chlorophyll a (Table 1).

Pigmentation encroached from the periphery of the bleached area in flow treated samples. Chlorophyll a increased in flow-treated colonies throughout the study and changed little in still treatments. Chlorophyll $C_{2}$, however, increased slightly in flow treatments in the last $2 \mathrm{wk}$ of the experimental period. Notably, there were no differences in total chlorophyll $C_{2}$ concentration between still and flow controls (Fig. 2). The flow treatment also showed a strong positive (logarithmic) relationship between the number of zooxanthellae per unit area and chlorophyll a concentration per unit area (Fig. 3). Chlorophyll a per zooxanthella increased only in flow treatments during the first $3 \mathrm{wk}$, and then declined, while chlorophyll a per zooxanthella declined over time in still treatments (Fig. 4). Chlorophyll $C_{2}$ per zooxanthella showed declines over time in both still and flow treatments (Fig. 4). Fig. 5 shows that there was little change in chlorophyll $a: c_{2}$ in still conditions, while flow conditions induced a rapid increase in a: $C_{2}$ during the first $5 \mathrm{wk}$, followed by a decline.

Discussion. Chlorophyll concentration and number of zooxanthellae per area were reduced in patches of Stylophora pistillata colonies exposed to high and prolonged light exposure. Recovery of chlorophyll concentrations and number of zooxanthellae was most apparent in flow-treated colonies. Recovery occurred firstly through an increase in chlorophyll a followed by an increase in the zooxanthellae population. Although full recovery was not achieved in $7 \mathrm{wk}$, the recovery rate was significantly higher in the flow-treated samples; however, the chlorophyll concentration per zooxanthella decreased as an inverse function of zooxanthellae number per area. These results agree with those of Fitt et al. (1993) and Jones (1997), who both showed an inverse relationship between algal cell number and chlorophyll a concentrations during recovery from coral bleaching. Furthermore, the flow conditions induced a rapid increase in $a: C_{2}$ during the

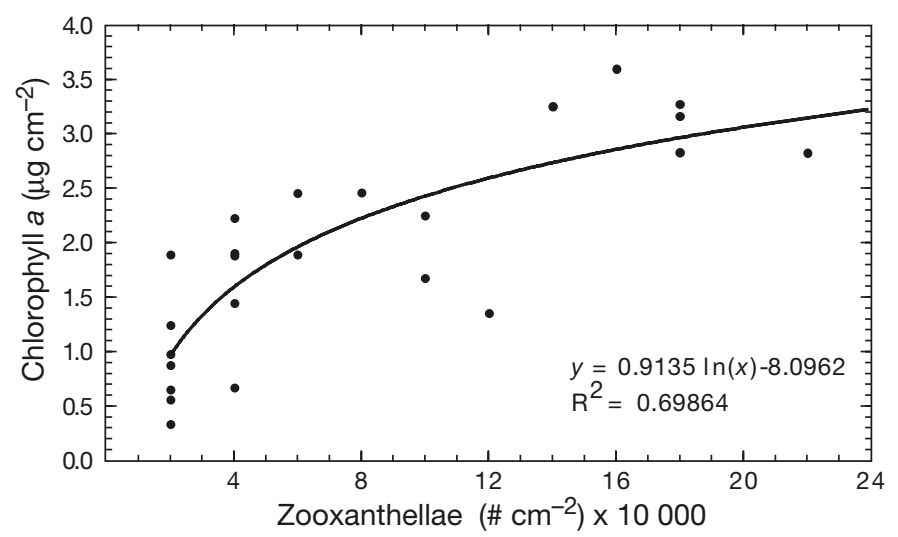

Fig. 3. Stylophora pistillata. Chlorophyll a concentration in relation to number of zooxanthellae in flow $\left(20 \mathrm{~cm} \mathrm{~s}^{-1}\right)$ treatment. Logarithmic response curve fitted using least-squares 

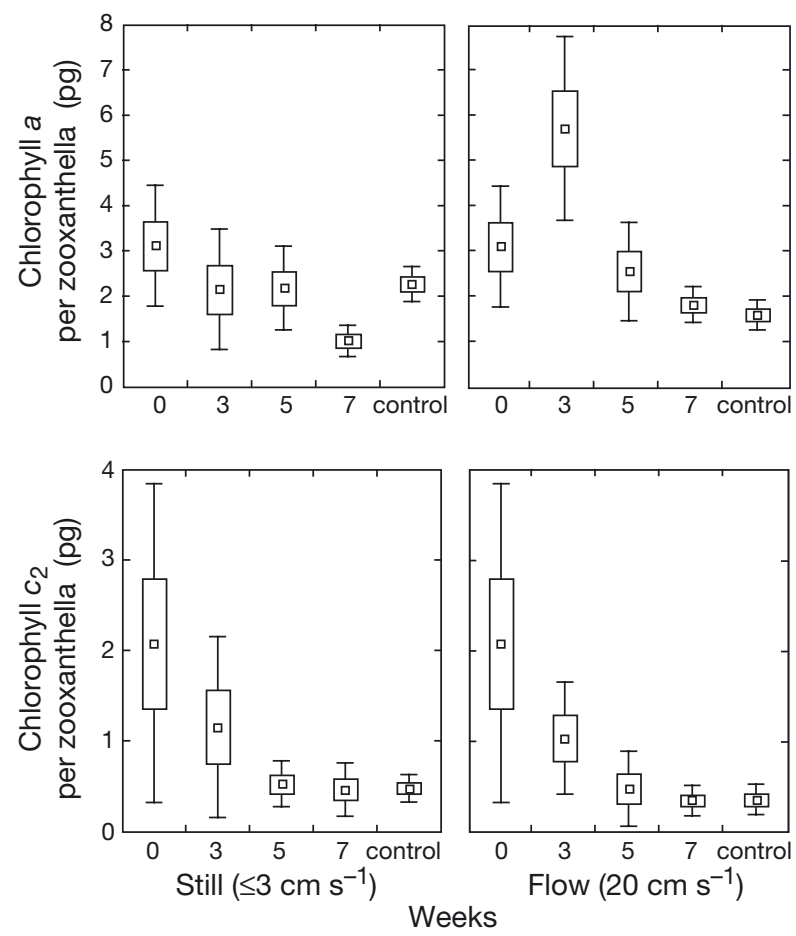

Fig. 4. Stylophora pistillata. Changes in chlorophyll a and $C_{2}$ concentration per zooxanthella in still and flow treatments over 7 wk $(n=3)$. Symbols as in Fig. 1

first 5 wk followed by a decline (Fig. 4), while there was little change in chlorophyll $a: c_{2}$ in still conditions. The changes in $a: c_{2}$ in the flow treatment suggests the algae are initially more high-light acclimated, and then photoacclimate to lower light as cell shading occurs by an increase in the number of zooxanthellae. These results agree with those of Brown (unpubl. data reported in Brown [1997]), who hypothesized that reduced chlorophyll $C_{2}$ values are associated with exposure to high radiant flux.

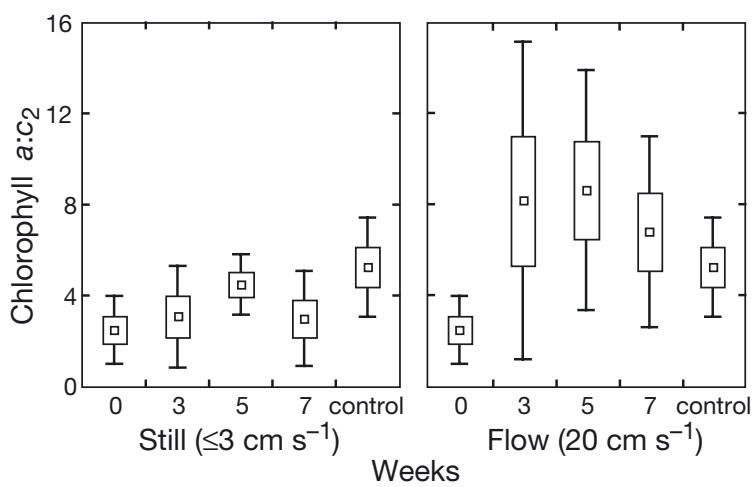

Fig. 5. Stylophora pistillata. Changes in chlorophyll a: $c_{2}$ in still and flow treatments over 7 wk $(n=3)$. Symbols as in Fig. 1
Within the coral host, zooxanthellae numbers can recover by 1 of 2 processes: (1) mitosis of remnant zooxanthellae within photodamaged tissue, or (2) encroachment of zooxanthellae from adjacent nonphotodamaged tissue. While chlorophyll degradation products are not discriminated from intact chlorophyll a using this conventional spectrophotometer technique (a facet that could result in artificially high pigment concentrations), there were clear differences in chlorophyll concentrations between the 2 flow treatments. Therefore, we suggest that recovery, in this study, was mainly through new peripheral algae encroaching into the open space (Fig. 1).

Previously, Nakamura \& Van Woesik (2001) showed that bleaching is prevented under moderate-to-high water-flow rates when corals are subjected to high SSTs (up to $33^{\circ} \mathrm{C}$ ) and high irradiance. In the present study, flow facilitated the recovery of zooxanthellae populations, most probably by enhancing mass-transfer rates of gases and molecules. Under high temperature and high irradiance, low water-flow rates cause slow mass transfer, and carbon fixation may be reduced significantly, either through the dark reactions of the Calvin cycle (see Jones et al. 1998) leading to stress at Photosystem II (PS II) and consequential photoinhibition of photosynthesis and bleaching, or because D1 proteins in the thylakoid membranes may become dysfunctional leading to direct photoinhibition of photosynthesis in PS II (see Warner et al. 1999). The present study has shown that the mechanisms of coral bleaching and recovery extend beyond mere temperature-light effects, since the rate of water flow alters the rate of mass transfer which, in turn, modifies any adverse effects of temperature and light. Indeed, the prevention of and rapid recovery from bleaching induced by moderate-to-high flow rates suggests that mechanisms that lead to dysfunction of the algae-coral symbiosis are driven by mass-transfer-limited processes.

Acknowledgements. We thank Dr. Shunichi Takahashi for experimental advice and Mark Warner and 4 reviewers for very useful comments on the manuscript. This work was supported by a Grant-in-Aid of Scientific Research (B) (No. 12480166) to R. van Woesik and H. Yamasaki from the Ministry of Education, Culture, Sports, Science, and Technology, Japan.

\section{LITERATURE CITED}

Atkinson MJ, Bilger RW (1992) Effects of water velocity on phosphate uptake in coral reef-flat communities. Limnol Oceanogr 37:273-279

Brown BE (1997) Coral bleaching: causes and consequences. Coral Reefs 16:129-138

Dennison WC, Barnes DJ (1988) Effect of water motion on coral photosynthesis and calcification. J Exp Mar Biol Ecol 115:67-77

Fitt WK, Warner ME (1995) Bleaching patterns of four species 
of Caribbean reef corals. (Biol Bull Woods Hole) 189: 298-307

Fitt WK, Spero HJ, Halas J, White MW, Porter JW (1993) Recovery of the coral Montastrea annularis in the Florida Keys after the 1987 Caribbean 'bleaching event'. Coral Reefs 12:57-64

Glynn PW (1991) Coral reef bleaching in the 1980s and possible connections with global warming. Trends Ecol Evol 6:175-179

Glynn PW (1993) Coral bleaching: ecological perspectives. Coral Reefs 12:1-17

Hearn CJ, Atkinson MJ, Falter JL (2001) A physical derivation of nutrient-uptake rates in coral reefs: effects of roughness and waves. Coral Reefs 20:347-356

Hoegh-Guldberg O (1999) Climate change, coral bleaching and the future of the world's coral reefs. Mar Freshw Res 50:839-866

Hoegh-Guldberg O, Smith GJ (1989) The effect of sudden changes in temperature, light and salinity on the population density and export of zooxanthellae from the reef corals Stylophora pistillata Esper and Seriatopora hystrix Dana. J Exp Mar Biol Ecol 129:279-304

Jeffrey SW, Humphrey GF (1975) New spectrophotometric equations for determining chlorophylls $a, b, c_{1}$, and $c_{2}$ in higher plants, algae and natural phytoplankton. Biochem Physiol Pflanz (BPP) 167:191-194

Johannes RE, Wiebe WJ (1970) A method for determination of coral tissue biomass and composition. Liminol Oceanogr 21:540-647

Jokiel PL (1978) Effects of water motion on reef corals. J Exp Mar Biol Ecol 35:87-97

Jones RJ (1997) Changes in zooxanthellar densities and chlorophyll concentrations in corals during and after a bleaching event. Mar Ecol Prog Ser 158:51-59

Jones RJ, Hoegh-Guldberg O, Larkum AWD, Schreiber U (1998) Temperature-induced bleaching of corals begins with impairment of the $\mathrm{CO}_{2}$ fixation mechanism in zooxanthellae. Plant Cell Environ 21:1219-1230

Editorial responsibility: Charles Birkeland (Contributing Editor), Honolulu, Hawaii, USA
Kuffner IB (2001) Effects of ultraviolet radiation and water motion on the reef coral Porites compressa Dana: a flume experiment. Mar Biol 138:467-476

Kuffner IB (2002) Effects of ultraviolet radiation and water motion on the reef coral, Porites compressa Dana: a transplantation experiment. J Exp Mar Biol Ecol 270:147-169

Kuroki T, Van Woesik R (1999) Changes in zooxanthellae characteristics in the coral Stylophora pistillata during the 1998 bleaching event. Galaxea 1:97-101

Kushmaro A, Loya Y, Fine M, Rosenberg E (1996) Bacterial infection and coral bleaching. Nature 380:396

Lesser MP, Weis VM, Patterson MR, Jokiel PL (1994) Effects of morphology and water motion on carbon delivery and productivity in the reef coral, Pocillopora damicornis (Linnaeus): diffusion barriers, inorganic carbon limitation, and biochemical plasticity. J Exp Mar Biol Ecol 178: 153-179

Marsh JA (1970) Primary productivity of reef-building calcareous and red algae. Ecology 55:225-263

Nakamura T, Van Woesik R (2001) Water-flow rates and passive diffusion partially explain differential survival of corals during 1998 bleaching event. Mar Ecol Prog Ser 212:301-304

Patterson MR (1992) A mass-transfer explanation of metabolic scaling relations in some aquatic invertebrates and algae. Science 255:1421-1423

Patterson MR, Sebens KP (1989) Forced convection modulates gas exchange in cnidarians. Proc Natl Acad Sci USA 86: 8833-8836

Patterson MR, Sebens KP, Olson RR (1991) In situ measurements of flow effects on primary production and dark respiration in reef corals. Limnol Oceanogr 36 (5):936-948

Yamasaki H, Heshiki R, Ikehara N (1995) Leaf-goldening induced by high light in Ficus microcarpa L. f., a tropical fig. J Plant Res 108:171-180

Warner ME, Fitt WK, Schmidt GW (1999) Damage to Photosystem II in symbiotic dinoflagellates: a determinant of coral bleaching. Proc Natl Acad Sci USA 96:8007-8012

Submitted: December 5, 2002; Accepted: March 13, 2003

Proofs received from author(s): June 30, 2003 